\title{
Effect of drill speed on the strain distribution during drilling of bovine and human bones
}

\author{
Maria G. Fernandes", Elza M. Fonseca ${ }^{* *}$, Renato N. Jorge ${ }^{* * *}$, Maria C. \\ Manzanares ${ }^{* * * *}$, Maria I. Dias ${ }^{* * * * *}$
}

* INEGI, Faculty of Engineering of University of Porto, Rua Dr. Roberto Frias, Campus da FEUP, 400, 4200-465 Porto, Portugal; mariagoreti_fernandes@hotmail.com,

** LAETA, INEGI, Department of Applied Mechanics, Polytechnic Institute of Bragança, Campus de Santa Apolónia, Apartado 134, $5301-857$ Bragança, Portugal; efonseca@ipb.pt

*** LAETA, INEGI, Department of Mechanical Engineering, Faculty of Engineering of University of Porto, Rua Dr. Roberto Frias, Campus da FEUP, 400, 4200-465 Porto, Portugal; rnatal@fe.up.pt

**** Department of Pathology and Experimental Terapeuthics,Faculty of Medicine and Health Sciences, University of Barcelona, Campus de Bellvitge,08907, Barcelona, Spain; mcmanzanares@ub.edu

***** CITAB, Department of Veterinary Sciences, School of Agrarian and Veterinary Sciences, University of Tras-os-Montes and Alto Douro, Quinta de Prados, 5001-801 Vila Real, Portugal; idias@utad.pt

\section{Special Issue- "Biomechanics"}

\begin{abstract}
Drilling is an operation commonly required in orthopaedic surgery for insertion of screws and internal fixation of bone fractures. Induced damage is one of the undesired effects of drilling mainly due to the use of inadequate drilling parameters. During the recent years, scientists have been trying to describe the relationship between drilling parameters and bone injury. However, no studies have examined the level of strain generated in the bone during the drilling process. This paper focuses on the analysis of different drill speeds during drilling of fresh bovine femora and human cadaveric tibiae. The main contribution of this work is to determine how differences in applied drill speeds affect the strain of cortical tissue near the drilling site and the drill bit temperature. Strains were measured in ex-vivo material during the osteotomy preparation with three drill speeds (520, 900 and 1370 r.p.m.). Additionally, a thermographic camera was used to measure the drill bit temperature. As the drilling operations are blind in nature with unknown depth, the osteotomies were performed using a drill press machine without control of the feed rate or depth. Drill bit geometry was kept constant with $4 \mathrm{~mm}$ of diameter, point angle $120^{\circ}$ and helix angle $30^{\circ}$. The tests were conducted at room temperature without applying cooling at the drilling zone. Bone strains near to the drilling sites were recorded with high accuracy using linear strain gages mounted around the diaphyseal cortex. It was noted that the bone strain and drill bit temperature increased with an increasing drill speed. Human and bovine bone samples presented significantly different levels of strain and temperature. Both strain and temperature were higher when drilling bovine femora than when drilling human cadaveric tibiae. DOI: https://doi.org/10.24243/JMEB/2.5.170
\end{abstract}

$\underline{\text { Research Article }}$

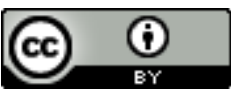

2018. Published by Rational Publication.

This work is licensed under the Creative Commons Attribution 4.0 International License. To view a copy of this license, visit https://creativecommons.org/licenses/by/4.0/ or send a letter to Creative Commons, PO Box 1866, Mountain View, CA 94042, USA.

Keywords: osteotomy; ex-vivo bones drill speed; bone strain; drill bit temperature

*Corresponding Author: Maria G. Fernandes Email Address: mariagoreti_fernandes@hotmail.com 


\section{Introduction}

The induced damage from the interface between bone tissue and cutting tool in surgical drilling procedures has been investigated for years. Prediction and control of bone drilling forces and heat generation have been the main concerns when evaluating the drilling performance [1], [2]. It is currently known that the drilling parameters such as drill speed, feed rate, drill geometry, the use of irrigation, predrilling, cortical thickness and bone density have significant influence on bone injury [1]. However, bone drilling in orthopaedic surgery is performed manually without detecting drilling force or depth and the drilling quality mainly depends on surgeon's manual skills. Drill speed is one of the parameters that can be controlled and generally recommended by the manufacturer. Studies have shown that high speeds result in increased trauma [3]-[5].Nevertheless, the literature review on the drill speed during drilling suggests no consistent trend [1]. Few studies have examined the effect of drill speed in human bone and no studies have inquired into this aspect for the strain magnitude during drilling. The challenges on bone drilling should not be limited to avoid thermal damage or excessive drilling forces but also to predict the strains affecting the bone tissue.

The present study is focused on an experimental methodology to analyse the effect of different drill speeds on the strain generation when drilling bovine femora and human cadaveric tibiae. Simultaneously, the temperature distribution on the drill bit surface was measured with the thermography equipment. This research complement our previous contributions in bone drilling [4]-[10].

\section{Materials and Methods}

\subsection{Bone samples preparation}

Ex-vivo study was performed on fresh middle diaphysis segments of bovine femur and non-embalmed sections of human cadaveric tibiae as the test models.

The human cadaveric tibiae were obtained with the permission of the author's institutional research ethics board. The tibiae samples were processed in the Body Donor's Service and Dissection Room of the University of Barcelona. Human tibiae were stripped of soft tissues and then visually inspected to exclude bone pathology. Donor medical histories, when available, were accessed to verify the absence of bone pathology, see Fig.1(a). The cortical thickness were measured with an average of $3.5 \mathrm{~mm}$. Similar values were found in the literature [11].

Bovine femora were selected since it's considered the closest animal bone to replicate the characteristics of the human osteonal remodelling process [12]. No animals were sacrificed for the current ex-vivo study, the bones were acquired in the local slaughterhouse. Samples represented in Fig.1(b)were formed from femur diaphysis with average cortical thickness of $6 \mathrm{~mm}$. In order to preserve their thermo-mechanical characteristics, all samples were maintained in saline solution and stored in plastic bags at $-4{ }^{\circ} \mathrm{C}$ according to the guidelines specified in [13]. Prior to the experimental tests, the samples were completely thawed at room temperature for 24 hours.

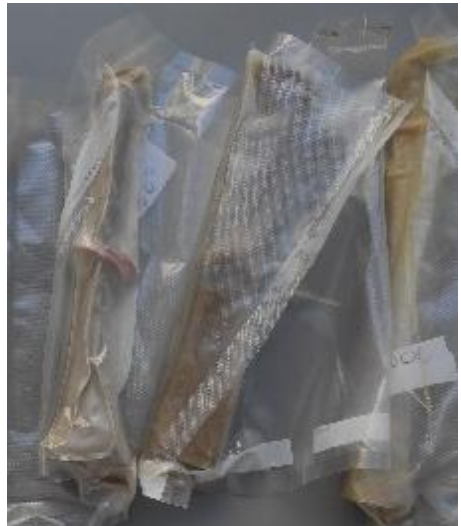

a)

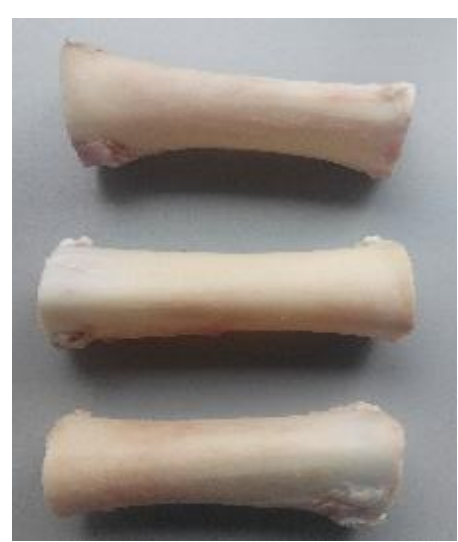

b)

Fig. 1 Bone samples used for ex-vivo study: a) human cadaveric tibiae and b) bovine femora from mid-diaphysis 


\subsection{Drilling tests and strain measurements}

The drilling tests were carried out in a vertical drilling machine with options of regulation of drill speed. The osteotomies were made with a drill bit ( $\varnothing 4 \mathrm{~mm}$, point angle of $118^{\circ}$ and helix angle of $30^{\circ}$ ) and drill speed rates of 520 , 900 and 1370 r.p.m. The selection of bone drilling parameters is based on the existing clinical practice based on handheld drilling machines. This way, feed rate and osteotomy depth depend on the sensibility of the operator. To obtain the feed rate, drilling time and osteotomy depth were measured with an appropriate depth gauge and the average for each sample was calculated. All experiments started from room temperature $\left(20-24^{\circ} \mathrm{C}\right)$ without any coolant. Between successive experiments, sufficient time was allowed for the bone tissue and the drill bit return to room temperature.

The strain measurements during bone drilling were made through linear strain gauges (1-LY18-6/120, $120 \Omega \pm 0.35 \%$ from HBM). The strain gauges were bonded directly to the bone surface. A small amount of adhesive was applied to the strain gauge, which is immediately placed in the prepared surface of the bone being careful to observe a correct alignment. To promote the uniformity of results, all gauges were mounted in identical locations, considering the same distance of $3.5 \mathrm{~mm}$ between the edge of the osteotomy and the middle of the strain gauge (Fig. 2). An acquisition data system (Vishay Micro Measurements P3 Strain Indicator and Recorder) allowed recording the strains during drilling.

Temperature measurements were also considered in the present study. A thermal camera (Therma CAM 365, FLIR Systems) was positioned at a distance of $1.5 \mathrm{~m}$ from the drilling area and allowed to obtain thermal images of the drill bit surface, before and immediately after drilling. The overall experimental setup for bone drilling is shown in Fig. 2. Measurements for each combination of machining parameters were randomly repeated six times.

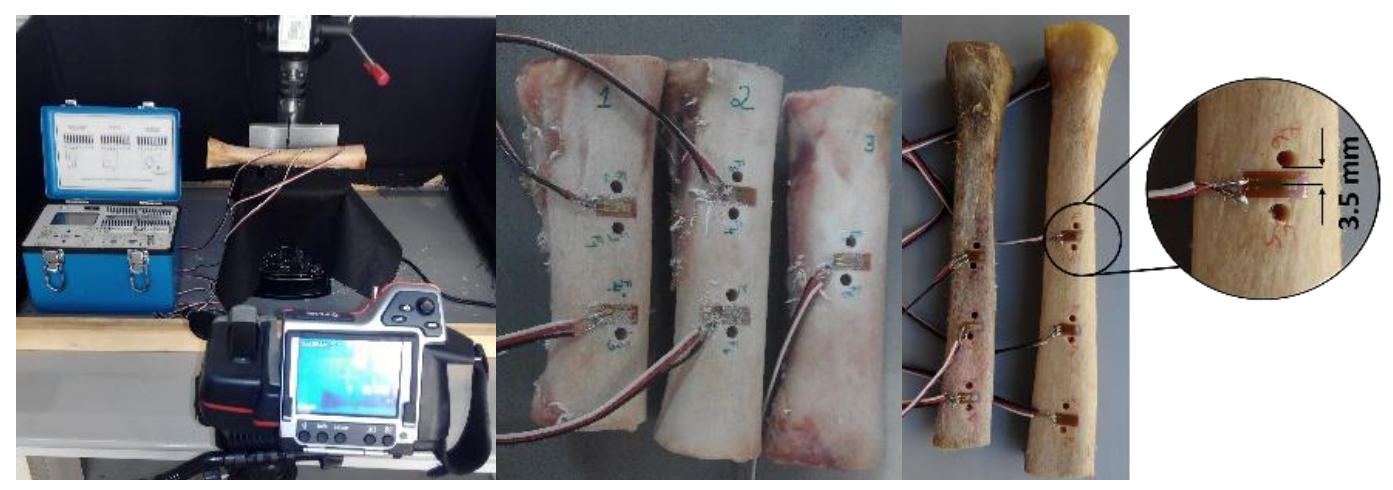

Fig. 2 Drilling tests on bone samples and strain measurements

\section{Results and Discussion}

Significant differences in the strain and temperature measurements were found in bovine and human bone samples as drill speed varied. Comparisons of the maximum strain values average are presented in Fig. 3. It became evident that changing the drill speed directly impacts the strain generated at the bone surface close to drilling zone. Overall, increasing the drill speed resulted in an increase in maximum bone strain. In the case of human cadaveric tibia, it was observed that when the drill speed was increased from 520 to 900 r.p.m. the strain increased by $19.95 \%$ and when the speed was increased from 900 to 1370 r.p.m. the strain increased by $58.34 \%$. In the case of the bovine femora, the increase of bone strain is still more accentuated than in human cadaveric tibiae. Strain increased significantly as the drill speed was changed from 520 to 1370 r.p.m. Comparing the level of strain for different drill speeds, it was observed that when the drill speed increased from 520 to 900 r.p.m. the strain increased by $47.67 \%$ and when the drill speed increase from 900 to 1370 r.p.m. the strain increased by $98.80 \%$. The authors of this study found similar trends in the polyurethane foams with mechanical properties similar to the cadaveric human bone, including FE studies [4].

To display the relations of drilling speed and drill bit temperature, the temperature variation was calculated and compared subtracting the recorded temperature (TR) with the initial temperature of the drill bit (T0) for each osteotomy 
$(\Delta \mathrm{T})$. The results were summarized using means values of $\Delta \mathrm{T}$. Fig. 4 shows the result of $\Delta \mathrm{T}$ considering the different drill speeds and bone tissues. It was observed that the drill bit temperature increased with increasing drill speed. By carrying out this analysis, it can be expected that the bone temperature also increased with the increase in drill speed. One explanation for these results could be that the number of cuts and the amount of friction between the drill and the bone will be relatively increased, thus leading to a higher accumulated friction energy and a higher bone temperature rise. These outcomes are consistent with our already published works, using bovine and porcine bones [10]. In addition, other authors suggest the same results [14].

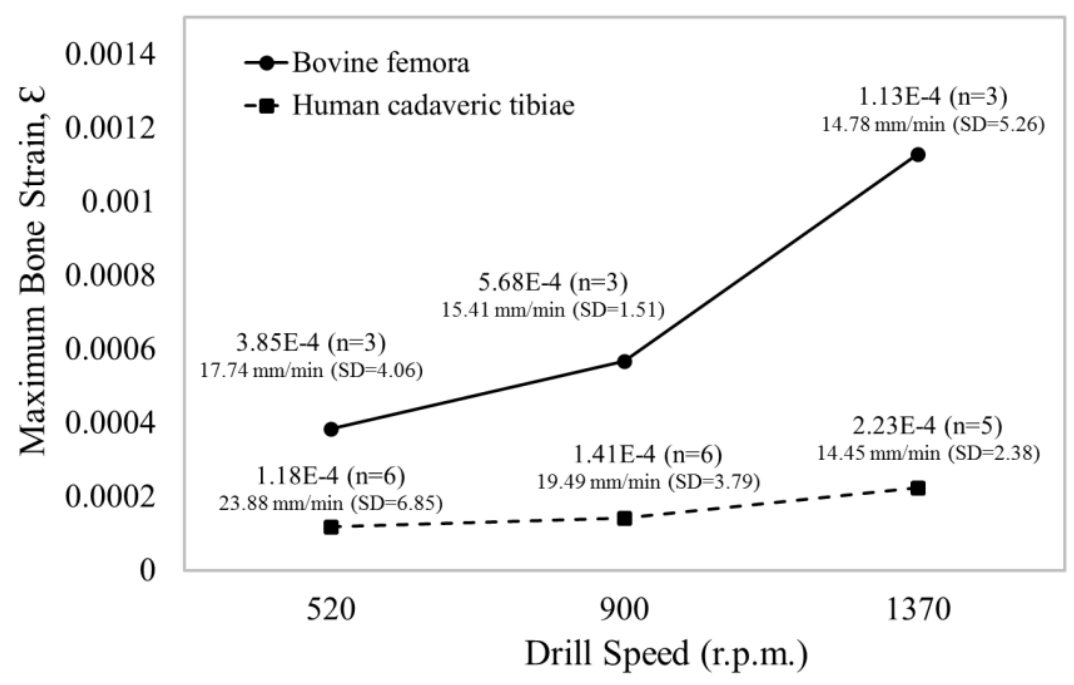

Fig. 3 Bone strains as a function of drill speed and bone tissue, $n$ number of holes, mean of feed rate (SD) in mm/min

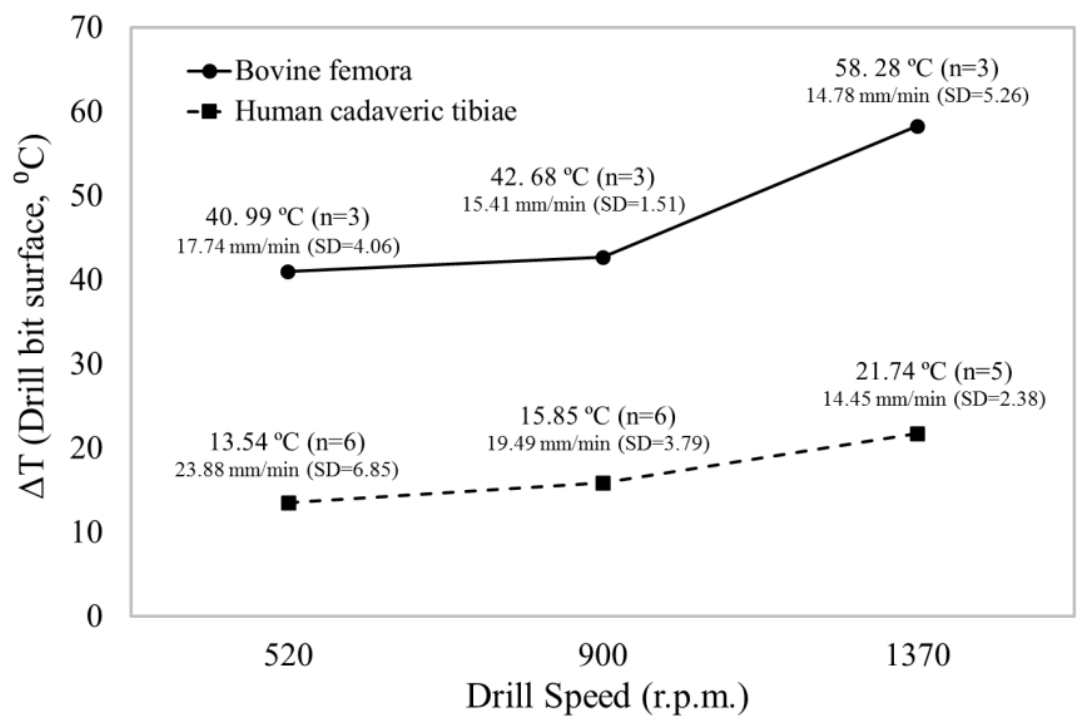

Fig. 4 Drill bit temperature as a function of drill speed and bone tissue, $n$ number of holes, mean of feed rate (SD) in mm/min

Concerning bovine femora versus human cadaveric tibiae, their behaviour show a similar trend both for strains and drill bit temperatures. However, the strain and drill bit temperature generated when drilling bovine femora were higher than that produced when drilling human cadaveric tibiae. This behaviour has been expected, since the bovine 
femur is much harder and the depth of the cortical thickness is greater than the human bone. The average cortical thickness for the bovine femorawas $6 \mathrm{~mm}$ while for the human cadaveric tibiae was $3.5 \mathrm{~mm}$.

\section{Conclusions}

Analysis of the relationship between drilling conditions and strain or temperature rise are crucial to prevent bone injury during the osteotomy. This study demonstrated the interaction on the effect of different drill speeds in the bone strain and drill bit temperature generation during drilling of bovine femora and human cadaveric tibiae. The parameters for the drilling tests included three drill speeds and feed rates obtained by the manual drilling, as it happens in clinical practice. The use of different drill speeds and the inherent variations of bone material properties bring a strong variation on the strain magnitudes and drill bit temperatures.

In general, it was observed that an increase in the drill speed could raise the bone strain and the drill bit temperature during bone drilling. Both bone strain and drill bit temperature were higher when drilling the bovine femora than when drilling human cadaveric tibiae. Variability in bone properties and mainly in the cortical thickness lead to significantly variations on the strains and temperatures during drilling. Lastly, the results from the present study can provide reference values for the development of new surgical power tools in orthopaedic bone surgeries application.

\section{Acknowledgements}

This research was supported by the Portuguese Foundation of Science and Technology under the research project UID/EMS/50022/2013. The authors acknowledge the funding of Project NORTE-01-0145-FEDER-000022 - SciTech Science and Technology for Competitive and Sustainable Industries, NORTE2020, through Fundo Europeu de Desenvolvimento Regional (FEDER). The authors gratefully acknowledge the generosity of the body donors.

\section{Funding}

This research no received specific grant from any funding agency in the public, commercial, or not-for-profit sectors.

\section{References}

[1] Pandey RK, Panda SS. Drilling of bone: A comprehensive review. Journal of clinical orthopaedics and trauma. 2013 Mar 31;4(1):15-30. DOI: https://doi.org/10.1016/j.jcot.2013.01.002

[2] Lee J, Gozen BA, Ozdoganlar OB. Modeling and experimentation of bone drilling forces. Journal of biomechanics. 2012 Apr 5;45(6):1076-83. DOI: https://doi.org/10.1016/j.jbiomech.2011.12.012

[3] Augustin G, Davila S, Mihoci K, Udiljak T, Vedrina DS, Antabak A. Thermal osteonecrosis and bone drilling parameters revisited. Archives of Orthopaedic and Trauma Surgery. 2008 Jan 128(1):71-7. DOI: https://doi.org/10.1007/s00402-007$\underline{0427-3}$

[4] Fernandes MG, Fonseca EM, Jorge RN. Thermo-mechanical stresses distribution on bone drilling: Numerical and experimental procedures. Proceedings of the Institution of Mechanical Engineers, Part L: Journal of Materials: Design and Applications. 2017 Jan 13:1464420716689337. DOI: https://doi.org/10.1177/1464420716689337

[5] Fernandes MG, Fonseca EMM, Jorge RN. Assessment of different drill diameter on bone drilling. Journal of Mechanical Engineering and Biomechanics. 2017 1(6):135-141. DOI: https://doi.org/10/24243/JMEB/6.1.151

[6] Fernandes MG, Fonseca EM, Natal RJ. Thermal analysis during bone drilling using rigid polyurethane foams: numerical and experimental methodologies. Journal of the Brazilian Society of Mechanical Sciences and Engineering. 2016 Oct 1;38(7):1855-63. DOI: https://doi.org/10.1007/s40430-016-0560-4

[7] Fernandes MG, Fonseca EM, Natal RM. Three-dimensional dynamic finite element and experimental models for drilling processes. Proceedings of the Institution of Mechanical Engineers, Part L: Journal of Materials Design and Applications. 2015 Sep 29:1464420715609363. DOI: https://doi.org/10.1177/1464420715609363

[8] Fernandes MG, Fonseca EM, Natal RM. Vaz M, Dias MI. Thermal analysis in drilling of ex vivo bovine bones. Journal of Mechanics in Medicine and Biology. 2017 Aug 17(5): 1750082-98. DOI: https://doi.org/10.1142/S0219519417500828

[9] Azevedo LD, Fernandes MG, Fonseca EMM, Jorge RN. Tensões em materiais sólidos de espumas de poliuretano rígidas sob furação. RevistaIberoamericana de IngenieríaMecánica. 2016 20(2):35-43. ISSN 1137-2729 
[10] Fernandes MG, Natal RJ, Fonseca EMM, Dias MI. Temperature assessment in the drilling of ex vivo bovine and porcine cortical bone tissue. BioMedWomen: Proceedings of the international Conference on Clinical and BioEngineering for women's Health, Natal Jorge et al. (Eds), CRC Press, Taylor \& Francis Group, London, pp. 159-163. ISBN 978-1-13802910-1.

[11] Gauthier R, Aubonnet R, Bala Y, Vallet Q, Bochud N, Minonzio J, Rongieras F, Follet H, Laugier P, Mitton D. Human tibial cortical thickness can predict its strength. 22nd Congress of the European Society of Biomechanics, July 10-13, 2016, Lyon, France

[12] Currey JD. Bones: structure and mechanics, Princeton University Press, Princeton 2006

[13] Yuehuei AH, Robert DA. Mechanical testing of bone and the bone-implant interface. New York: CRC Press, p. 178-179, 2000.

[14] Chen YC, Hsiao CK, Ciou JS, Tsai YJ, Tu YK. Effects of implant drilling parameters for pilot and twist drills on temperature rise in bone analog and alveolar bones. Medical Engineering \& Physics. 2016 Nov 38(11):1314-1321. DOI: https://doi.org/10.1016/j.medengphy.2016.08.009 